\title{
SCOR: What Is IT AND What Does It Do?
}

\author{
By Elizabeth Gross and Terry Healy
}

\begin{abstract}
A LThOUGH MANY TOS members may be accustomed to working within the context of the large international programs and are aware of the role and achievements of SCOR (the Scientific Committee on Oceanic Research), the purposes and operation of this organization may not always be readily identified or appreciated by the community-at-large. This brief article is designed to provide some information on SCOR-what it is and what it does for the international ocean sciences community.
\end{abstract}

Oceanographers have a long tradition of international cooperation, in part because of the need to optimize the use of expensive facilities. Modern collaboration dates back at least to the International Indian Ocean Expedition of the early 1960s. Founded in 1957, SCOR is the oldest interdisciplinary committee of the International Council of Scientific Unions (ICSU), and the Indian Ocean effort was one of SCOR's earliest initiatives.

Over the four decades of its existence, SCOR has served primarily as a body that facilitates international cooperation in oceanography. It does this in a number of ways, most of which involve the use of a limited budget to bring together groups of individuals to discuss a variety of scientific problems. With thirty to forty such meetings a year, the SCOR Secretariat often seems more like a travel agency than anything else!

There are now fifteen active SCOR Working Groups, and the list of all past and present working groups totals more than 100 . The groups are established to address a fairly narrow yet scientifically important and timely topic which can benefit from the attention of a small, fo-

Elizabeth Gross, Executive Director and Terry Healy, Vice President, SCOR Department of Earth and Planetary Sciences, The John Hopkins University, Baltimore, MD 21218, USA. cused international group. SCOR groups have also taken the lead in resolving questions of methods and standards in ocean science. For example, the Practical Salinity Scale and the related International Equation of State of Seawater were developed by a SCOR panel. An idea of the range of SCOR's current scientific activities can be gained from the list of current working groups and committees in Table 1.

These Working Groups generally have about 10 members and will meet two or three times. Their final product may be a publication in the primary scientific literature, such as a book or a special volume of a journal, or the organization of a major international conference or workshop with an associated publication. Recently, SCOR WG 97 on Harmful Algal Blooms received a substantial award from NATO to organize an Advanced Study Institute to take place at the Bermuda Biological Station in mid-1996. WG 96 on Acoustic Monitoring of the World Ocean has served a valuable role in facilitating international participation, bringing the Russians, Chinese, and others into the planning process for the Acoustic Thermometry of Ocean Climate program begun by Walter Munk following the successful Heard Island Feasibility Study. The 1995 meeting of the SCOR Executive Committee will consider a proposal for a new working group on the coupling of winds, waves, and currents in coastal ocean models, a problem which has long frustrated coastal oceanographers.

Working Groups are established by SCOR on the basis of proposals received from national committees, other organizations, or even from individual scientists. These proposals are carefully reviewed at the annual meetings of SCOR along with comments received from national committees and other sources be- fore a decision is taken to set up a new group. Scientific priorities must be balanced within the constraints of a budget that limits the number of groups SCOR can support. The progress of each working group is reviewed annually, but at the biennial General Meeting of SCOR every group is assumed to be disbanded unless its report presents adequate justification for its continuation. This procedure has increased the efficiency of our Working Groups and is a model which other international organizations are beginning to emulate.

Working Group activities may result in recommendations for more substantial programs that will last longer than the normal life span of a SCOR Working Group. One example is the program on Acoustic Thermometry of Ocean Climate (ATOC) mentioned above. ATOC is a large scale experiment using the characteristics of sound-wave propagation across large distances in the ocean as a method to detect whether ocean warming on a global scale is occurring. Another is IMAGES (International Marine Global Change Study), under the joint sponsorship of SCOR and PAGES (Past Global Changes, another Core Project of the IGBP). The IMAGES scientific plan arose from the SCOR Working Group 100 on Sediment Coring for International Global Change Research. SCOR is currently considering a new way of continuing its sponsorship of these long-term international efforts without unduly stressing its limited financial resources.

SCOR does not and cannot run large research programs; it simply does not have the budget or personnel to do so. Indeed, SCOR spends a comparatively small proportion of its funds on administration. Rather, it prefers to initiate and nurture the establishment of programs, providing coordination and administrative support during the early planning stages, 
Table 1

The current scientific activities of SCOR-1995

WG 86 Ecology of Sea Ice (with SCAR and AOSB)

WG 89 Sea Level Rise and Erosion of the World's Coastlines (with IOC)

WG 93 Pelagic Biogeography (with IOC and ICES)

WG 95 Sediment Suspension and Sea Bed Properties

WG 96

WG 97

WG 98

Acoustic Monitoring of the World Ocean (with IOC)

Physiological Ecology of Harmful Algal Blooms (with IOC)

Worldwide Large-scale Fluctuations of Sardine and Anchovy Populations (with IOC)

WG 99 Linked Mass and Energy Fluxes at Ridge Crests

WG 100 Sediment Coring for International Global Change Research (with PAGES/IGBP)

WG 101 Influence of Sea State on the Atmospheric Drag Coefficient (with IOC)

WG 102 Comparative Salinity and Density of the Atlantic and Pacific Ocean Basins

WG 103 The Role of Wave Breaking on Upper Oean Dynamics

WG 104 Coral Reefs Responses to Global Change: The Role of Adaptation

WG 105 The Impact of World fisheries Harvests on the Stability and Diversity of Marine Ecosystems

WG 106 Relative Sea Level and Muddy Coasts of the World

JGOFS Scientific Steering Committee for the Joint Global Ocean Flux Study (with IGBP)

GLOBEC Scientific Steering Committee for Global Ocean Ecosystem Dynamics (with IOC)
Stephen F. Ackley (USA)

Paul Komar (USA)

Annalies Pierrot-Bults

(The Netherlands)

Gerhard Graf (Germany)

David Farmer (Canada)

Donald Anderson (USA)

Daniel Lluch-Belda (Mexico);

Robert Crawford (S. Africa)

Martin Sinha (UK)

Nick Pisias (USA)

Ian Jones (Australia): Yoshiaki Toba (Japan)

Frank Millero (USA)

Mike Banner (Australia)

Bob Buddemeier (USA)

Michael Sinclair (Canada)

Yin Wang (China)

John Field (S. Africa);

Liliane Merlivat (France)

Brian Rothschild (USA) stepping back as the programs gather their own momentum and find their own sources of funding. However, the administrative credibility of SCOR has prompted some agencies in the U.S. and elsewhere to allocate funds to SCOR for the planning of such programs.

Two contemporary examples of SCORsponsored large-scale programs are international JGOFS (Joint Global Ocean Flux Study) and GLOBEC (Global Ocean Ecosystem Dynamics), both of which have been discussed in previous issues of this magazine. The early affiliation of these programs with SCOR provided an efficient mechanism for international coordination and the involvement of many new countries in these programs. Established in 1987, JGOFS has been a Core Project of the International Geosphere-Biosphere Program (IGBP) since 1989, and SCOR is currently seeking similar status for GLOBEC. The World Ocean Circulation Experiment (WOCE) and the Tropical Ocean-Global Atmosphere programs of the World Climate Research Program had their beginnings in about 1980 in the Committee on Climatic Changes and the Ocean, established by SCOR and the IOC in 1979. So, to a large extent, the early planning and coordination of the oceanic global change research programs has been a SCOR effort.
Of course, SCOR is not always the only sponsor of these programs and often works in partnership with the intergovernmental community as represented by organizations such as the Intergovernmental Oceanographic Commission of UNESCO, the International Council for the Exploration of the Sea, and others. In fact, SCOR serves as an official scientific advisory body to the IOC, and the two organizations have many joint activities, as can be seen in Table 1.

SCOR consists of its "members" - the national committees for oceanic research of its 39-member countries, each of which is represented by three individual oceanographers. The biennial General Meetings elect an Executive Committee, which includes ex officio members from allied disciplinary organizations, namely, IAPSO (International Association for Physical Sciences of the Ocean), IABO (International Association for Biological Oceanography), CMG (Commission for Marine Geology), and IAMAS (International Association for Meteorological and Atmospheric Sciences). Membership in SCOR is open to all countries with active oceanographic research communities. National committees are usually associated with a nongovernmental institution, such as an Academy of Sciences. Indeed, it is a condition of membership that the national adhering body demonstrate that it is representative of a broad range of oceanic research activities. There are five levels of national membership dues, each country being permitted to choose its own level; this relates to factors such as the size of the country, its GNP, the extent of its EEZ, and the importance each places on its interest in, and responsibility for, the global oceans.

The membership dues provide some of the operating funds for SCOR. Additional funds have in the past been generated by grants and contracts from funding agencies, national members, and other international organizations. One such award from the U.S. National Science Foundation supports a program of travel grants to marine scientists from developing countries and the countries of the former Soviet Union. More than thirty such grants per year allow these oceanographers to join their colleagues from more privileged nations at international scientific meetings.

The SCOR Secretariat is located in the Department of Earth and Planetary Sciences of The Johns Hopkins University in Baltimore, and is staffed by an Executive Director and an Executive Assistant. Its prime function is to provide routine administrative support for SCOR activities. In addition to publications such as the JGOFS Report Series and the GLOBEC Report Series, the secretariat also produces the SCOR Proceedings, an annual account of all SCOR activities and organizational matters, and the directory or SCOR Handbook.

Although SCOR may not maintain a high profile with frequent glossy publications and so on, it quietly goes about its tasks, perhaps too frequently unnoticed by many oceanographers. As it approaches its 40th anniversary, the members of SCOR should look with pride on its accomplishments. The organization has often played a pivotal role in identifying ocean research issues, in undertaking reviews of important problems brought to it by the scientific community, and in fostering and coordinating major global ocean research programs. SCOR has gained wide respect from those who are familiar with its successes, and it continues to be sought as a sponsor of important scientific activities where international cooperation is needed.

For more information please contact: Elizabeth Gross, Executive Director, SCOR Department of Earth and Planetary Sciences, The Johns Hopkins University, Baltimore, MD 21218, USA. Tel: (410) 516-4070/Fax: (410) 516-4019 / E-mail: scor@jhu.edu $\square$ 